\title{
Instituições e grupos de interesse: a União Europeia nas negociações agrícolas da Rodada Doha (2001-2005)
}

Institutions and interest groups: European Union in Doha Round agriculture negotiation (2001-2005)

MARIA IZABEL VALLADÃO DE CARVALHO*

Rev. Bras. Polít. Int. 54 (2): 212-229 [2011]

\section{Introdução}

A partir da Rodada Uruguai e da criação da Organização Mundial do Comércio (OMC), a agenda do comércio internacional tornou-se mais complexa e incluiu número maior de temas para ser acordado. Além disso, o foco das negociações foi ampliado para abranger a regulação de políticas internas que pudessem ter efeitos nas trocas comerciais externas. Em consequência, o impacto das negociações de comércio internacional sobre os interesses dos estados nacionais aumentou. A intensificação da interdependência, trazida pela globalização e pela liberalização econômica e comercial, também cooperou para que os custos e benefícios das negociações de comércio se tornassem mais visíveis para os setores domésticos afetados e incentivou o envolvimento de atores não governamentais em questôes de negociação comercial externa.

Contudo, os processos de mobilização de tais atores não resultam de forma imediata em decisōes governamentais favoráveis a eles. Diversamente dos estudos que enfatizam o "pluralismo econômico, em que os resultados políticos são uma função do conflito político moldado pelas preferências de diferentes atores, pesadas pelo seu poder de mercado e sua propensão à ação coletiva" (Garret e Lange 1996, 49), este artigo destaca o papel das instituições como fator que condiciona a influência das preferências de atores não governamentais nas negociações multilaterais de comércio.

Instituições são conceituadas como regras que modelam a interação entre atores burocráticos, políticos e sociais (Milner 1997). As regras para a tomada de decisão no âmbito da política comercial externa da União Europeia (UE) instituem

\footnotetext{
* Professora Dra. do Instituto de Relaçôes Internacionais (IREL) da Universidade de Brasília (UnB).
} 
limites para a atuação de atores burocráticos e governamentais como também os capacitam. Isto é, proporcionam a esses atores poderes para decidir. Tais poderes (como, por exemplo, o poder de agenda - de propor um mandato negociador -, de conduzir as negociações de um acordo multilateral, e de aprovar o mandato e o acordo negociado internacionalmente) conferem aos atores referidos capacidade para agir.

Além disso, as regras estabelecem um processo decisório complexo em que as preferências de diferentes atores precisam ser compatibilizadas: entre os atores burocráticos que compõem a Comissão Europeia (Comissão); entre esses atores e os representantes dos Estados-membros no Conselho da União Europeia (Conselho); e entre os ministros dos Estados-membros dentro do Conselho. Por conseguinte, vários jogos de barganha se desenvolvem nesses diferentes âmbitos. Tais jogos abrangem conflitos entre posiçóes mais ou menos protecionistas, bem como sobre as consequências distributivas no contexto doméstico dos Estados-membros das posturas defendidas pela $\mathrm{UE}^{1}$ no contexto internacional.

As regras decisórias também condicionam o comportamento dos grupos de interesse. O poder de iniciativa da Comissão torna esse órgão um espaço central para a ação dos grupos de interesse. O Conselho, por sua vez, abre espaço para uma atuação indireta dessas organizações que vão procurar afetar os representantes dos Estados por meio de pressóes domésticas. Como salientam alguns autores, a atuação durante o processo de ratificação dos acordos negociados externamente são menos eficazes do que as pressões exercidas sobre a Comissão, pois naquela fase do processo decisório as posições já estão consolidadas e é mais difícil modificá-las.

Os grupos de interesse também acionam recursos para fazer valer suas preferências. Eles envolvem, por exemplo, apoio financeiro para campanhas eleitorais e mobilização da opinião pública e são acionados com o objetivo de influenciar o comportamento dos atores políticos. Os grupos de interesse ainda se mobilizam para pressionar os agentes burocráticos. Nesse caso, o conhecimento técnico sobre um determinado assunto ou a capacidade de bloquear ou dificultar a efetivação de uma política pública são mecanismos de pressão não desprezíveis.

Estudos sobre a relação entre a Comissão e os grupos de interesse destacam que: (i) os grupos de interesses proveem, muitas vezes, informação e conhecimento técnico para a Comissão; e (ii) os produtores rurais são poderosos porque eles podem

\footnotetext{
1 A União Europeia designa formalmente o ator que está encarregado da política comercial comum, inclusive em suas ações internacionais. A Comissão, por meio da Direção Geral de Comércio, negocia em nome da UE os acordos bilaterais, regionais e multilaterais. Para isso, ela atua de acordo com um mandado concedido pelo Conselho. Dessa maneira a posição defendida pela UE no contexto das negociações resulta de um processo de compatibilização entre as preferências da Comissão e do Conselho. Isso não significa que a Comissão, por meio do Comissário de Comércio Exterior, aja sempre de acordo com o mandato. Na Rodada em pauta, em algumas ocasiōes, o Comissário foi acusado por alguns Estados de não estar respeitando o mandato. Essas acusaçôes não redundaram na destituição do Conselho, mas indicaram que a relação entre a Comissão e o Conselho envolveu conflitos. Essas questôes, ainda que relevantes, não foram objeto deste estudo. Quando, porém, elas forem mencionadas, será usado o termo Comissão no lugar de UE.
} 
impedir ou dificultar a realização de uma política agrícola estabelecida no âmbito da UE (Hoffmann 2003, 63-64). Dessa forma, as organizações representativas dos produtores rurais são relevantes e não devem ser descartadas.

Porém, os poderes dos atores burocráticos e governamentais definidos institucionalmente proporcionam a esses atores autonomia relativa frente às pressões dos grupos de interesse do setor agrícola. Os poderes possibilitam aos atores referidos avançar preferências que não necessariamente convergem com as das organizações agrícolas. Como será abordada na segunda seção deste estudo, a Comissão defendeu posiçõos mais liberalizantes em relação às reformas da Política Agrícola Comum (PAC) que não foram encampadas pelos grupos de interesse dos produtores rurais. Também durante as negociaçōes sobre agricultura na Rodada, o Comissário para Comércio Exterior da UE, que negocia em nome da UE, foi acusado em diversos momentos pela França de defender proposições que iam além do mandado que lhe fora concedido pelo Conselho. Isso significou que aquele ator sustentou posturas que ameaçavam interesses protecionistas de parte dos Estadosmembros em relação ao funcionamento do mercado agrícola europeu.

Este artigo versa sobre a influência do Comitê das Organizaçôes Profissionais Agrícolas e do Comitê Geral da Cooperação Agrícola (Copa-Cogeca), o euro-grupo mais antigo de representação dos interesses dos produtores rurais no âmbito da UE, nas posições encaminhadas por esse ator em três Conferências Ministeriais da Rodada Doha - Doha (2001), Cancun (2003) e Hong Kong (2005) - e referente ao Acordo-Quadro adotado pelo Conselho Geral da OMC em 2004. Por conseguinte, não é tratado, no artigo, o papel dos grupos de interesse nacionais e que atuam no ambiente doméstico dos Estados-membros.

O objetivo da investigação foi avaliar a intervenção das preferências do Copa-Cogeca nas posturas adotadas pela UE nas transaçôes que ocorreram nas três Conferências Ministeriais e no Acordo-Quadro, ambos referidos anteriormente. Para isso, as preferências do Copa-Cogeca foram cotejadas com as defendidas pela UE no contexto da Rodada. As mudanças que ocorreram na PAC também foram analisadas. Investigaram-se, nesse caso, as posições do Copa-Cogeca diante das propostas defendidas pela Comissão e dos resultados alcançados pelas reformas. Cabe ressaltar que o processo negociador entre os grupos de interesse e os diversos atores que compõem a estrutura institucional comunitária da UE, ainda que relevante, não foi objeto de estudo desta pesquisa.

Argumenta-se que as diferenças de posicionamentos encontradas, inclusive as relativas às reformulações da PAC, podem ser explicadas a partir de componentes institucionais do processo decisório da UE destacados anteriormente e elaborados na primeira seção deste artigo. Desse modo, sugere-se que a influência do CopaCogeca na posição defendida pela Comissão desde o início da Rodada Doha e até a Conferência Ministerial em Hong Kong não foi determinante, ainda que não se possa dizer que tenha sido irrelevante. As pressões do grupo de interesse reduziram a amplitude das mudanças na PAC e afetaram as propostas negociadoras apresentadas 
pela UE no nível da Rodada Doha. Porém, tais pressões não impediram que avanços se efetivassem nesses dois contextos.

Na primeira parte do artigo, o processo decisório da UE na esfera da política comercial externa, o papel da PAC nas posições adotadas por esse ator nas negociações da Rodada Uruguai e Doha até 2005 e o relacionamento entre o Copa-Cogeca e o processo decisório referido são analisados.

$\mathrm{Na}$ seção seguinte examinam-se os posicionamentos vocalizados pelo CopaCogeca frente às reformas da PAC (Agenda 2000 e Reforma de Meio Período em 2003) e diante do processo negociador da Rodada Doha. Tais posicionamentos são, por sua vez, cotejados com as posições tomadas pela Comissão e pelo Conselho em relação aos dois processos negociadores mencionados. A conclusão ressalta os resultados encontrados e sugere algumas consequências para a aprovação de um possível acordo agrícola no âmbito da UE.

\section{Processo decisório, a PAC e o lobby agrícola na UE}

Esta parte do artigo divide-se em três seções. Na primeira seção, o processo de tomada de decisão da UE é analisado com o objetivo de demonstrar que ele contém elementos que reduzem a capacidade de influência do Copa-Cogeca nas decisōes referentes à política comercial externa.

Em seguida, examinam-se os fatores que interferiram no surgimento e na evolução do Copa-Cogeca. Ressalta-se o papel das reformas da PAC no enfraquecimento da capacidade de ingerência do grupo de interesse dos produtores agrícolas. Por último, as vias utilizadas pelo Copa-Cogeca para influenciar o comportamento dos membros da Comissão e do Conselho são investigadas, bem como são destacados os óbices presentes nas etapas da formulação de políticas da UE para que as pressões daquela agremiação sejam eficazes.

As instituiçôes da UE foram delineadas para manter um delicado equilíbrio entre, por um lado, o estabelecimento de mecanismos supranacionais e, por outro lado, as demandas e os interesses dos Estados-membros. Como destaca Smith $(2003,230)$ : "Esta tensão, entre a vontade de agir coletivamente no palco internacional e o desejo de reter autonomia nacional, modelou as instituiçóes desenvolvidas no campo das relaçôes externas, bem como os resultados produzidos por aquelas instituiçôes."

Apesar de a política comercial externa ser uma política comunitária por excelência, a tensão mencionada anteriormente está presente no seu funcionamento. A delegação de poderes à Comissão no âmbito da política comercial externa foi acompanhada pela instituição de mecanismos de monitoramento do comportamento desse ator pelos Estados-membros. Além disso, os Estadosmembros mantiveram, por meio dos poderes do Conselho, o poder de vetar o acordo negociado internacionalmente. 
A Comissão, por meio da Direção Geral de Comércio Exterior, exerce o poder de propor um mandato negociador e de conduzir as negociações internacionais. O Conselho de Negócios Estrangeiros (CNE), órgão do Conselho da União Europeia e integrado pelos Ministros de Relaçôes Exteriores dos Estados-membros, aprova o mandato negociador e o acordo negociado pela Comissão.

As principais etapas do processo decisório, bem como os papéis desempenhados por seus atores principais, podem ser resumidas da seguinte maneira (White 2001, 51):

1. A Comissão propõe ao CNE uma recomendação com os objetivos referentes às negociações no contexto da OMC.

2. A recomendação é discutida junto ao Comitê dos Representantes Permanentes (Coreper), composto pelos embaixadores ou funcionários graduados dos Estados-membros sediados em Genebra, que pode modificá-la.

3. O CNE pode decidir ou não prosseguir. Essa decisão é tomada por uma maioria qualificada. ${ }^{2}$ Caso o resultado tenha sido positivo, o CNE indica à Comissão as diretivas para desenvolver as negociações. Tais diretivas constituem o que se convencionou chamar de mandato negociador.

4. A condução das negociações externas pela Comissão é efetivada em constante interação com o "Comitê 207" da Política Comercial - comitê de alto nível nomeado pelo Conselho e constituído por funcionários graduados dos Estados-membros na área de comércio exterior. ${ }^{3}$ Além disso, a Comissão, frente à presença de dificuldades do processo negociador, pode voltar ao CNE e esse órgão modificar o mandato inicial.

5. O acordo concluído internacionalmente é encaminhado pela Comissão ao CNE. Mas só a CNE tem o poder de assiná-lo.

6. O CNE decide sobre o acordo pela regra da maioria qualificada ou da unanimidade. Em áreas em que os Estados não acordaram uma posição comunitária, o CNE decide sob a regra da unanimidade. Tais áreas compreendem: propriedade intelectual, investimento direto estrangeiro, serviços, serviços audiovisual e cultural, e serviços social, educacional e de saúde.

O Parlamento é consultado durante todo o processo de negociação e dá o seu consentimento antes da votação do Conselho. Contudo, ele não tem o poder de aprovar acordos comerciais.

2 Maioria qualificada diz respeito a um sistema de votos ponderado pela população dos Estados-membros. Existe uma maioria qualificada quando ela atinge 255 do total de 345 votos e abrange 14 membros. Qualquer Estado pode solicitar verificação de que aquela maioria representa $62 \%$. Caso isso não ocorra, a decisão não é votada. <http://www.consilium.europa.eu>. Disponibilidade: 10 de março de 2011.

3 O “Comitê 207" faz referência ao artigo 207 do Tratado de Funcionamento da União Europeia (União Europeia 2010) que trata da política comercial externa <http://eur-lex.europa.eu/LexUriServ/LexUriServ.do?uri=OJ:C:20 10:083:0047:0200:EN:PDF>. Disponibilidade: 10 de março de 2011. 
A proposta de autorização comercial é preparada na Direção Geral de Comércio e discutida no âmbito dos vários setores da Comissão que, direta ou indiretamente, são afetados pelas negociaçôes em curso. A Comissão abrange 27 Direções Gerais, entre elas a de Agricultura e Desenvolvimento Rural, Empresas e Indústrias, e Mercado Interno e Serviços. A proposta de mandato precisa, em consequência, compor os objetivos negociadores para agricultura com os de outros setores como, por exemplo, indústria e serviços.

Como o mandato implica delegação do Conselho à Comissão para negociar e resulta de um compromisso entre os Estados-membros, ele geralmente é delineado de forma bastante rigorosa.

Para Doha, a autorização foi discutida e organizada tendo em vista a posição média dos membros do Conselho. Além disso, o Presidente do Conselho da União Europeia - que possui também capacidade de agência, como será destacado mais tarde - decidiu que, antes de ser enviado ao CNE, o mandato para Doha deveria ser encaminhado ao Conselho de Agricultura (órgão do Conselho da União Europeia e constituído pelos Ministros de Agricultura dos Estados-membros) para aprovação. Tais cuidados resultaram na ratificação da autorização sem mudanças no CNE. ${ }^{4}$

Naquele momento, o mandato para agricultura foi bastante restritivo porque o Conselho ainda não tinha aprovado uma reforma da PAC. As reformas efetuadas a partir da Agenda 2000 e pela Reforma de Meio Período permitiram que a posição defendida pela Comissão evoluísse, o que poderá ser observado na segunda parte do artigo.

Ainda que se possa formar uma minoria bloqueadora quando a questão é decidida por maioria qualificada, e que seja suficiente que um Estado se oponha ao que está sendo votado para que a questão seja rejeitada sob a regra da unanimidade, os representantes dos Estados-membros precisam buscar o compromisso no Conselho. É necessário que os Estados cooperem entre si para que os interesses de todos sejam alcançados.

É verdade que a regra da unanimidade permite aos Estados possuidores de posição mais próxima do status quo exercer o poder de veto sobre o acordo negociado (Tsebelis 2002). Porém, a regra da unanimidade também possibilita que, em questões sensíveis para as preferências de determinados Estados, eles possam ser escutados.

É claro que países muito comprometidos com a PAC, como é o caso da França, dificultam avanços maiores nas reformas da PAC, bem como nas posições defendidas pela Comissão na Rodada Doha. Apesar de não ser objeto do artigo analisar o caso da França, vale salientar dois fatores que podem explicar o seu comportamento. Primeiro, a França é o maior exportador agrícola da UE e é o Estado que mais recebe recursos proporcionados pela PAC (Comission Européenne 2006). Além disso, a organização representativa dos interesses dos produtores rurais

4 Entrevista realizada pela autora com funcionário sênior da Comissão Europeia em 2007. 
franceses, a Federação Nacional dos Sindicatos de Produtores Rurais (FNSEA), organizada localmente, representa cerca de $10 \%$ da população de produtores agrícolas da UE-25 (ibid.) e é um ator não desprezível nas eleições francesas.

Por último, mas não menos importante, destaca-se o papel relevante do Conselho Europeu, formado pelos chefes de governo e de Estado dos Estadosmembros, e pelo Presidente do Conselho da União Europeia em decisōes finais que podem afetar a PAC e as negociaçóes multilaterais de comércio.

Durante a Rodada Uruguai, duas decisões do Presidente do Conselho da União Europeia foram cruciais para que o Acordo Blair House pudesse ser $^{5}$ efetivado. Primeiro, ele estabeleceu que o Acordo fosse examinado em uma sessão "jumbo" do Conselho, à qual estavam presentes os ministros de relaçôes exteriores, de agricultura e de comércio dos Estados-membros, antes que fosse encaminhado para deliberação no CNE. Em segundo lugar, o Presidente do Conselho decidiu que a ratificação do Acordo ocorresse sob a regra da unanimidade (White 2001, 68).

Tais decisões ainda precisaram ser complementadas com compensaçôes econômicas estendidas à França e a Portugal para que o CNE aprovasse o Acordo da Rodada Uruguai (ibid.). Porém, elas demonstram o papel relevante que o Presidente do Conselho da União Europeia pode ter, interferindo no processo decisório da política comercial comum e mudando o curso dos acontecimentos. Além disso, ao trazer a França para o âmbito decisório, por meio da mudança da regra, ele possibilitou que o processo, ainda que difícil, fosse deslanchado.

A influência do Copa-Cogeca na formação da política comercial externa da UE é, por conseguinte, filtrada por uma estrutura institucional em que os Estadosmembros, além de procurarem defender seus interesses - ou seja, estarem sensíveis às preferências do ambiente doméstico -, precisam também cooperar para atingilos. Além disso, o modo como o mandato é preparado e decidido implica que ele expresse a compatibilização das preferências dos atores burocráticos no âmbito da Comissão com as dos representantes dos Estados-membros no contexto do Conselho. Tais preferências não convergem em sua totalidade com as do CopaCogeca, como se procurará demonstrar na segunda parte do artigo. O CopaCogeca atua em âmbito institucional complexo, com atores que não partilham necessariamente suas preferências e com poderes decisórios que a organização não possui. Esses fatores são relevantes, ainda que não os únicos, para demonstrar que o processo decisório da UE media as pressóes do euro-grupo representativo dos produtores rurais.

Dificilmente é possível discorrer sobre o desempenho da UE nas negociações internacionais de comércio no âmbito da agricultura e nas reformas da PAC sem que o papel das organizaçōes defensoras das demandas dos agricultores não seja destacado. (Moyer 1993; Paterson 1997; Peterson e Bomberg 1999; Rieger 2000; Foilleux 2003).

5 O Acordo Blair House foi acordado entre os EUA e a União Europeia e seus termos possibilitaram que as negociaçōes da Rodada Uruguai, até então interrompidas, prosperassem. 
As agremiações do setor agrícola que atuam no nível da UE (euro-grupos) são de vários tipos. Elas abrangem: representações de grupos de uma única nacionalidade, como, por exemplo, Irish Farmers' Association; organizações que reúnem produtores nacionais de um produto específico, como o Comité Européen des Fabricants de Sucre; e organizações que representam federações e associações nacionais de produtores rurais, como é o caso do Copa-Cogeca. Em 2000, existiam 129 euro-grupos defensores de interesses agrícolas. Apesar de numerosos, esses grupos representavam em 2003 menos da metade dos grupos industriais (289) e um terço dos grupos do setor de serviços (313) (Eising 2003, 198).

O Copa-Cogeca é o grupo mais antigo e bem organizado junto à UE como representante dos produtores rurais. Entre os 20 grupos de interesse empresariais que possuem mais de 20 funcionários em horário integral em seu escritório em Bruxelas, encontra-se o Copa-Cogeca (staff de 55 funcionários). Ele é, ainda, o único euro-grupo vinculado à agricultura na lista, onde ocupa posição de destaque ( $3^{\circ}$ lugar) (Greenwood 2003, 74). Atualmente, 60 organizaçôes dos Estados-membros (federações e organizações nacionais) estão filiados ao Copa e 35 ao Cogeca.

O Copa foi instituída em 6 de setembro de 1958 - um ano após a promulgação do Tratado de Roma, que estabeleceu a Comunidade Econômica Europeia (CEE). O Tratado de Roma delineou ainda a PAC e definiu seus objetivos. Também em 1958, a Conferência de Stresa designou os princípios que orientariam a efetivação da $\mathrm{PAC}$ tais como, por exemplo, a garantia de preço e os subsídios à exportação. Em 24 de setembro de 1959, as cooperativas agrícolas instituíram o Cogeca. E, em $1^{\circ}$ de dezembro de 1962 - quando a PAC entrou em vigor -, as duas organizações se fundiram.

A constituição das duas agremiações resultou da necessidade de se formar mecanismos representativos que relacionassem o processo decisório centralizado e burocratizado da PAC ao âmbito da Comissão com as necessidades dos produtores locais (Rieger 2000). Os procedimentos de formulação e implementação da PAC estavam sujeitos à obtenção de informações sobre a situação dos agricultores. Ademais, muitas decisões tomadas pela UE precisavam ser desenvolvidas ao nível local, o que dependia da aceitação dos produtores e de suas organizações de representação de interesse. ${ }^{6}$

As mudanças trazidas pelas Reformas da PAC de 1992, 2000 e 2003 restringiram parcialmente a ingerência dessas organizaçôes, pois iniciaram um processo de criar condições para que o mercado tivesse papel maior nas escolhas econômicas dos agentes produtivos. Uma medida significativa foi a desvinculação dos pagamentos diretos da produção, ainda que aplicada parcialmente e não em todos os produtos.

6 A operação da PAC dependia, por um lado, da fixação de preços para cada produto e, por outro lado, de agências nacionais encarregadas de comprar o excesso quando o preço chegasse a um determinado nível. Além disso, o preço da entrada de cada produto, bem como o valor que os produtores receberiam para exportar seus produtos a preços competitivos no mercado internacional, eram estabelecidos ao nível da UE. (Fouilleux 2003, 247-48). 
O processo decisório da UE permite que os grupos de interesse possam usar diferentes caminhos para influenciar o desempenho da Comissão e do Conselho. Eles podem ser conceituados como a via de Bruxelas, a via nacional e a via doméstica (Greenwood 2003). Por meio da primeira via, os grupos de interesse procuram pressionar diretamente os atores burocráticos e políticos ao nível comunitário da UE. No caso dos outros dois cursos, as pressões são indiretas: as agremiações acionam os governos nacionais e/ou elas desenvolvem alianças entre organizaçōes de diferentes nacionalidades para influenciar os seus governos e, dessa maneira, impactar nas decisōes tomadas no âmbito da UE.

Os diferentes caminhos de influência mencionados são efetivamente utilizados pelo Copa-Cogeca. Quando a política está sendo formulada na Comissão, como é o caso do mandato negociador e das reformas da PAC, as pressões da organização se direcionam para esse órgão.

Quando a política encontra-se na fase de aprovação no contexto do Conselho, a atuação indireta é mais frequente. Isto é, a organização concentra suas atividades na esfera doméstica dos Estados-membros por meio de pressões das agremiações nacionais sobre as autoridades governamentais e a mobilização da opinião pública. Dessa maneira, elas podem influenciar o comportamento dos representantes dos Estados-membros presentes no Conselho.

O poder de iniciativa da Comissão torna essa instituição a arena principal para a atuação dos euro-grupos. As etapas iniciais para a formulação de políticas abrangem "oportunidades para definir questôes como problemas, enquadrá-las de modos particulares e moldar rascunhos de políticas" (Greenwood 2003, 30). Porém, quando as decisóes chegam ao Conselho é "mais difícil exercer influência porque questôes já foram moldadas e as intervenções podem requerer mudanças em posiçóes definidas em lugar de buscar transformar problemas em iniciativas políticas." (ibid., 32).

Ademais, os representantes dos Estados-membros no Conselho decidem por negociação e compromisso. Nesse caso, eles trocam apoio entre eles, o que contribui para limitar as estratégias de pressão "nacional" e "doméstica" (ibid., 41-42). Dessa maneira, a atuação indireta do Copa-Cogeca sobre o Conselho é uma estratégia cujos efeitos são restritos, ainda que não irrelevantes.

Ressalte-se ainda que a presença de vários canais de acesso para os grupos de interesse significa que a UE caracteriza-se por um "processo político inerentemente desconectado". Acordos "fechados em um lugar institucional podem ser desfeitos em outro lugar" (Mazey e Richardson 2006, 265).

Em situações em que a regra de votação no Conselho é a unanimidade, os vínculos entre determinados governos nacionais e as organizaçôes agrícolas podem surtir efeitos significativos, como ocorreu no caso da Rodada Uruguai. Nas discussões que precederam a decisão final no Conselho, a França "insistiu e assegurou, em alguma extensão, um acordo agrícola que não fosse além dos termos acordados pela reforma da CAP de 1992" (White 2001, 68). 
Dessa maneira, o que se verifica é que a influência do Copa-Cogeca sobre as decisões que envolvem o interesse dos produtores rurais não é direta, mas intermediada por uma estrutura institucional complexa, com vários níveis decisórios e atores com poderes de decisão significativos. Tal estrutura institucional oferece possibilidades, mas também limites para que as pressóes do Copa-Cogeca sejam efetivadas. Não se pode deixar de destacar que os representantes dos governos nacionais no Conselho precisam atuar de modo integrado, o que implica compromisso entre preferências mais e menos protecionistas. Em consequência, a influência do Copa-Cogeca é relativa e dependente de vários fatores para se efetivar.

\section{UE e Copa-Cogeca: muito barulho por nada?}

Nesta seção, a ingerência do Copa-Cogeca nas posições tomadas pela UE nas três Conferências Ministeriais da OMC é investigada. Procura-se demonstrar que essa influência não foi determinante, pois se ocorreu convergência em alguns temas, em outros, mais centrais à agenda das negociaçóes, as divergências se instalaram.

Para se entender o impacto do Copa-Cogeca no desempenho da Comissão, é necessário considerar as reformas da PAC de 2000 e 2003 e as decisões do AcordoQuadro, aprovado pelo Conselho Geral da OMC em $1^{\circ}$ de agosto de 2004. Esse acordo estabeleceu a estrutura a partir da qual se desenvolveriam as transaçóes futuras e representou um turning point fundamental do processo negociador.

Inicialmente, é analisada a influência das Reformas da PAC nas posturas defendidas pela UE em cada uma das três Conferências Ministeriais da OMC (Doha, Cancun e Hong Kong) e nos resultados do Acordo-Quadro referido. Em seguida, investigam-se as posturas do Copa-Cogeca em relação à PAC e às posições da Comissão.

Três são os pilares a partir dos quais são processadas as negociações sobre agricultura na Rodada Doha: competição das exportaçôes, apoio doméstico e acesso a mercados. Competição das exportações refere-se aos diferentes tipos de instrumentos de apoio à exportação e que exercem efeitos negativos nas relações comerciais. Entre eles, incluem-se os subsídios às exportaçôes da UE, os créditos à exportação, empresas estatais de exportação, e programas de ajuda alimentar passíveis de serem utilizados como forma de administrar o excesso de oferta interna.

Em apoio doméstico, os programas de apoio que incentivam a produção e causam distorções no comércio são enfocados. No Acordo Agrícola da Rodada Uruguai, instituíram-se três categorias de medidas domésticas, denominadas caixa amarela, caixa azul e caixa verde. A primeira contém instrumentos que geram efeitos diretos sobre a produção e que, portanto, devem ser eliminados, ou significativamente reduzidos; a segunda inclui pagamentos aos agricultores associados a programas que limitam a produção e que podem ser mantidos se certas condições são satisfeitas; a terceira abrange resoluções que impactam de modo mínimo a produção e estão, por conseguinte, livres para serem utilizadas. 
$\mathrm{Na}$ Conferência de Doha, a Comissão se opôs à eliminação total dos subsídios à exportação e defendeu a manutenção da caixa azul - pois contemplava programas internos relativos à execução da PAC - e uma pequena redução no apoio doméstico claramente distorcivo, bem como a utilização da fórmula da Rodada Uruguai para a definição de como deveriam ser efetivados os cortes das tarifas agrícolas (European Communities 2000a, 2000b, 2000c).

Além do mais, a Comissão sustentou uma perspectiva ampla no tratamento dos subsídios à exportação. Isto é, essa questão, vinculada à situação da UE, precisaria ser focalizada junto com os outros instrumentos que pudessem, também, afetar negativamente a competição das exportações, como, por exemplo, créditos à exportação e programas de ajuda alimentar de efeitos distorcivos sobre o comércio internacional utilizados pelos EUA.

A Comissão defendeu também que preocupações não comerciais deveriam ser acopladas às negociaçôes sobre agricultura e conseguiu que tais preocupações fossem incluídas na Declaração Ministerial de Doha (WTO 2001).

A postura da UE para a Ministerial de Cancun permaneceu, em grande parte, a mesma que tinha sido formulada para Doha. Contudo, aquele ator manifestou uma mudança não desprezível, ainda que bastante tímida, concernente à questão da eliminação dos subsídios à exportação. Nesse sentido, na proposta apresentada em conjunto com os EUA (WTO 2003), a UE expressou, pela primeira vez, a intenção de eliminar os subsídios, ainda que em período determinado e para produtos específicos de interesse particular dos países desenvolvidos. É importante destacar que a evolução de uma posição bastante restritiva sobre essa questão na Ministerial de Doha ${ }^{7}$ para uma mais flexível, mas ainda bastante limitada na Ministerial de Cancun, está diretamente relacionada ao processo de mudança das regras da PAC que se processavam internamente no âmbito da UE.

No contexto da Agenda $2000^{8}$, a Comissão procurou introduzir, de forma abrangente, a desvinculação dos pagamentos aos agricultores da produção - um dos elementos essenciais de funcionamento da PAC desde o seu estabelecimento pelo Tratado de Roma (1957) e responsável pelas crises de superprodução e pela diminuição da competitividade da agricultura da UE. Porém, tal modificação não foi aprovada na reunião do Conselho Europeu - constituído pelos Chefes de Estado, pelos Chefes de Governo e pelo Presidente da União Europeia - em Berlim, em março de 1999 (Rieger 2000, 203).

\footnotetext{
$7 \mathrm{O}$ acordo de Doha esteve ameaçado de não se concretizar porque a UE recusou-se a incluir a expressão "phasing out" na Declaração Final, pois ela implicaria na eliminação total dos subsídios no término da Rodada. O consentimento da UE só foi obtido com a inclusão também da frase "sem prejulgar os resultados das negociaçōes", que em sua interpretação deixaria para o processo transacional a decisão sobre a eliminação total dos subsídios à exportação. (Amorim e Thorstensen 2001).

8 Em 1997, tendo em vista a perspectiva de alargamento futuro da UE para países do centro e leste da Europa, a Comissão Europeia propôs medidas para lidar com a ampliação da entidade, incluindo uma reforma da PAC e a sua adaptação aos novos membros. Tais medidas foram consubstanciadas no documento Agenda 2000: For a Stronger and Wider Union (Fouilleux 2003, 257).
} 
Contudo, os interesses mais amplos dos Estados-membros da UE em relação a uma nova rodada multilateral de comércio ${ }^{9}$, as pressões internacionais, e a percepção por parte da Comissão e dos Estados-membros da necessidade de adequar as regras da PAC a um contexto externo mais competitivo contribuíram para que a Comissão desencadeasse a Reforma de Meio Período da PAC, adotada em 26 de junho de 2003 pelo Conselho de Agricultura, órgão do Conselho integrado pelos Ministros de Agricultura da UE.

Ainda que se possa dizer que os objetivos da reforma foram diluídos, já que ela permitiu manter: i) um vínculo entre pagamentos diretos e produção (limitado); ii) o sistema de subsídios para determinados produtos, como cereais e carne bovina; e iii) um período de dois anos para que os Estados-membros se adaptassem às novas regras (European Commission 2003), a reforma representou, sob o foco da UE, mudança significativa. A desvinculação passou a ser incluída, de forma definitiva nas regras da PAC, e possibilitou que o mercado passasse a ter um papel maior nas decisões dos produtores rurais em relação à produção. A Reforma de Meio Período incluiu, também, um mecanismo de disciplina financeira de forma que o orçamento da PAC limitado até 2013 não fosse ultrapassado.

A aprovação da Reforma de Meio Período, às vésperas da Conferência da OMC em Cancun (de 10 a 14 de setembro de 2003), impediu o seu possível impacto na proposta defendida pela UE nessa Ministerial, pois um período de tempo se fazia necessário para que os Estados-membros absorvessem os efeitos domésticos das medidas contidas na reforma.

O Acordo-Quadro aprovado em $1^{\circ}$ de julho de 2004 pela OMC (WTO 2004) foi muito importante, considerando-se a evolução do desempenho da UE, porque nele se acordou: "que os membros estabelecerão modalidades detalhadas que garantam a eliminação em paralelo de todas as formas de subsídios à exportação e medidas com efeito equivalente em uma data a ser negociada" (Jank 2004). Além disso, o Acordo consentiu na permanência da caixa azul, para acomodar algumas medidas da Reforma da PAC, agora limitadas a 5\% do valor da produção agropecuária total e a alguns tipos de pagamentos diretos criados pela Lei Agrícola de 2002 dos EUA. Instituiu-se, ainda, um corte global não desprezível no teto dos subsídios domésticos distorcivos. (ibid.).

Em relação a acesso a mercados, os membros da OMC concordaram com a sugestão do G-20 de utilizar um sistema de corte tarifário em que as tarifas maiores teriam cortes mais profundos. Em consequência, abandonou-se a proposta da UE de usar a fórmula da Rodada Uruguai, a qual implicaria uma redução da média geral das bandas tarifárias.

A posição da UE para a Ministerial de Hong Kong baseou-se nas decisões do Acordo-Quadro e na Reforma de Meio Período da PAC, em andamento

9 A UE propugnou pela inclusão de vários temas na agenda das negociações, tais como relação entre comércio e investimento e comércio e concorrência, transparência em compras governamentais e facilitação de comércio. Essa agenda já presente na Conferência Ministerial em Seattle (1999) não se modificou para a Rodada Doha. 
desde o segundo semestre de 2003. Dessa maneira, ela manifestou disposição em eliminar os subsídios à exportação, desde que houvesse acordo para diminuições proporcionais nos outros instrumentos de apoio à exportação e que se chegasse a soluçôes satisfatórias em acessos a mercados e apoio doméstico. Porém, acabou defendendo como data para eliminação dos subsídios referidos o ano de 2013, quando o orçamento da PAC deveria ser revisto e uma nova reforma efetivada.

Desistiu, ainda, de insistir no emprego da fórmula da Rodada Uruguai para os cortes tarifários e apoiou as resoluçôes do Acordo-Quadro a esse respeito. Encaminhou, também, em 28 de outubro de 2005, a proposta de redução de $70 \%$ em subsídios domésticos distorcivos do comércio internacional - compatível com a Reforma de Meio Período - e um corte médio das tarifas em 46\%, sendo a mais alta de 60\% (Laws 2005).

As resoluções do Copa-Cogeca para as três Ministeriais divergiram parcialmente daquelas manifestadas pela UE. Para Doha, o Copa-Cogeca defendeu: i) que os resultados das negociações não deveriam ir além das decisões do Conselho Europeu em Berlim em 1999 a respeito da Agenda 2000; ii) a manutenção do apoio de preço e mercado; iii) a preferência comunitária como elementos centrais da $\mathrm{PAC}^{10}$; e iv) uma abordagem que contemplasse como equivalentes todos os instrumentos de apoio à exportação, seguindo, portanto, as posições defendidas pela UE (Copa-Cogeca 2000).

As duas reformulações da PAC ocorridas em 1999 e 2003 não foram bem recebidas pelas duas organizaçôes representativas dos interesses dos agricultores. Em relação à Reforma de Meio Período, elas defenderam a sua inadequação, tendo em vista a existência de mudanças em curso, provenientes da Agenda 2000, e se opuseram ao conteúdo da proposta da Comissão de ampliar o processo, de desvincular os pagamentos aos agricultores da atividade produtiva e de realizar cortes nos preços dos produtos agrícolas. (Copa-Cogeca 2001, 2003a).

Essas duas medidas levariam à redução ou ao abandono da produção em muitos setores agrícolas e ao desemprego, submetendo a maior parte dos produtores rurais à concorrência predatória dos produtores estrangeiros, que não seguiriam, segundo Copa-Cogeca, os mesmos padrões de produção exigidos pelos consumidores da UE.

Apesar da oposição do Copa-Cogeca, a Reforma de Meio Período, ainda que limitada, se concretizou.

As proposiçōes do Copa-Cogeca para Cancun foram: i) conservar a preferência comunitária - o que significava que a média dos cortes tarifários não poderia ser superior a 36\%; ii) oposição à eliminação total dos subsídios à exportação; iii) manutenção da perspectiva abrangente em relação ao tratamento dos subsídios; e

$10 \mathrm{O}$ sistema de apoio de preço e mercado relaciona-se à manutenção de um preço garantido para remuneração dos produtores agrícolas. A preferência comunitária refere-se, por sua vez, a níveis tarifários altos para impedir que as importaçôes ameacem o sistema interno de apoio de preços (Fouilleux 2003, 247-48). 
iv) que a oferta da UE em apoio doméstico não poderia ir além das reduções feitas na Reforma de Meio Período (Copa-Cogeca 2003b).

É importante destacar que: i) apesar de terem sido contrárias à Reforma de Meio Período, as duas organizações incorporaram o limite estabelecido por essa reforma ao seu posicionamento frente à Ministerial de Cancun; e ii) independentemente de suas posturas oposicionistas, o Acordo-Quadro de 2004 aprovou o estabelecimento de modalidades para a eliminação total dos subsídios à exportação, em data a ser negociada.

Em documento apresentado às vésperas da Conferência de Hong Kong, CopaCogeca deixou claras as suas insatisfações com as ofertas encaminhadas pela UE, já que tais ofertas não foram acompanhadas de movimentos similares dos adversários nas negociaçôes referentes à competição das exportações e apoio doméstico. Em relação a acesso a mercados, Copa-Cogeca deplorou que a UE “já ofereceu demais”. Somado a isso, as duas organizaçóes declararam que as ofertas da UE criariam enormes dificuldades para os agricultores europeus e suas cooperativas, já que os altos padrões de produção exigidos pelos consumidores europeus não poderiam ser alcançados por meio daquelas propostas (Copa_Cogeca 2005a).

Dessa maneira, diante de uma situação de fato - isto é, as ofertas da UE tinham se afastado das propostas das duas organizações -, Copa-Cogeca passou a propor a condicionalidade das ofertas e a não discussão de uma data para o fim dos subsídios até que as regras para o conjunto de instrumentos de apoio à exportação fossem acordadas.

Logo após os resultados da Conferência de Hong Kong, o presidente do Copa-Cogeca afirmou que o resultado foi "incompleto e parcial", pois não houve uma contrapartida satisfatória por parte dos outros parceiros da UE.

As duas organizaçóes defenderam, assim: i) o caráter condicional da data acertada (2013) para a eliminação dos subsídios à exportação da UE em relação às ofertas de seus adversários; ii) um período de eliminação dos subsídios à exportação da UE que assegurasse que os preços e o mercado agrícola não fossem desestabilizados; e iii) um resultado adequado para acesso a mercado "o qual não deve ir uma polegada além da oferta da UE em 28 de outubro de 2005" (Copa_Cogeca 2005b).

A estratégia do Copa-Cogeca em relação aos posicionamentos adotados pela UE na Rodada Doha até 2005 foi, por conseguinte, o de incorporar em suas demandas as decisóes já tomadas no âmbito da PAC e no patamar negociador em suas diferentes fases (Doha, Cancun, Acordo-Quadro e Hong Kong), e minimizar a partir de novas proposições os possíveis efeitos negativos das mesmas sobre os interesses de seus representados. Desse modo, a organização adotou a estratégia de redução de danos.

As posições da UE e do Copa-Cogeca em relação às preocupações com os aspectos não comerciais da agricultura e aos vínculos preferenciais com os países em desenvolvimento em todas as três Ministeriais foram mais convergentes do 
que ocorreu com os outros temas examinados. Os dois atores defenderam o caráter excepcional da agricultura vis-à-vis outras atividades produtivas, pois ela exerceria também funçôes não econômicas, tais como, por exemplo, a defesa do meio ambiente e da segurança dos alimentos, bem como contribuindo para o desenvolvimento do meio rural.

\section{Conclusão}

A relação entre os atores da UE e o Copa-Cogeca é complexa. Se, por um lado, Copa-Cogeca é um grupo cujas preferências não podem ser descartadas nas decisões sobre agricultura, por outro lado, o processo decisório da política comercial comum abrange atores com poderes e preferências que não necessariamente convergem com as do Copa-Cogeca.

Desse modo, as decisões tomadas pela UE na Reforma de Meio Período da PAC e no Acordo-Quadro no contexto da OMC distanciaram-se das posiçôes defendidas pelo Copa-Cogeca. Além disso, a organização optou por uma estratégia de redução de danos, na medida em que parte de seus posicionamentos não foram acatados pela UE nas Conferências Ministeriais da Rodada. Isso não significa que o comportamento da organização não foi irrelevante, mas que sua ingerência é relativa. Ainda que Copa-Cogeca não tenha podido frear avanços nas posições da UE, as suas pressões e protestos dificultam o aprofundamento daquelas medidas. Daí que a UE se move, mas em ritmo lento.

É relevante ressaltar que as posiçôes do Copa-Cogeca não encontram ressonância nas demandas de outras organizaçôes como, por exemplo, a Confederação das Indústrias Agro-Alimentares da UE (CIAA). Esse euro-grupo representa indústrias de alimentos e bebidas - maior setor industrial da UE -, as quais necessitam de acesso a matérias-primas a preços competitivos. A CIAA apresentou um posicionamento mais favorável à Reforma da PAC e às posturas endossadas pela UE nas negociações da Rodada Doha do que aquelas vocalizadas pelo Copa-Cogeca ${ }^{11}$.

Ademais, as propostas da Comissão para reformar a PAC e para o mandato negociador junto ao Conselho precisaram levar em conta outros interesses econômicos que não apenas os agrícolas. O contexto das negociações da Rodada Doha representou, ainda, um impulso significativo no processo de reforma da PAC, já que a capacidade da UE de extrair concessões de seus adversários dependeu do que esse ator pudesse oferecer na mesa de negociação.

Porém, os movimentos no sentido de maior flexibilização da posição negociadora sobre agricultura defendidas pela Comissão na Rodada foram

11 A CIAA defendeu: "redução substancial em todas as formas de apoio doméstico que distorcem o comércio internacional"; uma posição cautelosa na retirada dos subsídios à exportação, já que uma retirada abrupta desses subsídios "tornaria inviável a exportação em determinados setores da indústria”; redução tarifária que permitisse reais melhorias nas oportunidades de acesso ao mercado da indústria de alimentos e bebidas” (CIAA 2005). 
acompanhados de protestos por parte do Copa-Cogeca e da França (Minder e Alden 2005). A França lidera o grupo de Estados (Portugal, Espanha, Irlanda, Polônia e Itália) menos propenso a aceitar proposições que possam ameaçar a PAC e avançar no sentido de uma liberalização maior do mercado agrícola comunitário. A insatisfação da França, que vocaliza no âmbito intergovernamental a oposição dos grupos de interesse dos produtores rurais, sinaliza as dificuldades que enfrentará um possível acordo para ser aprovado pelo CNE.

\section{Referências bibliográficas}

AMORIM, Celso e THORSTENSEN, Vera. (2002) "Uma Avaliação Preliminar da Conferência de Doha: As Ambigüidades Construtivas da Agenda do Desenvolvimento". Politica Externa, Vol. 10, no 4 .

CARVALHO, Maria Izabel Valladão de. (2006) "Condicionantes Institucionais e Políticos e Poder de Barganha nas Negociações Internacionais sobre Agricultura: O Caso da União Européia”. Revista Brasileira de Política Internacional, Vol. 49, no. 2, p. 99-118.

CIAA (Confederação das Indústrias Agro-Alimentares da UE). (2005) CIAA priorities in the multilateral trade negotiations of the Doha Development Agenda <http://www.ciaa.be/asp/ documents/detailed_doc.asp?doc_id=567>. Disponibilidade: 14 de março de 2011.

COMMISSION EUROPÉENNE. (2006) l'Agriculture dans l'Union Européenne: Informations Statistiques et Économiques 2005. Luxembourg, Office des publications officielles des Communautés européennes.

COPA-COGECA. (2000) COPA and COGECA's Comments on the EC Comprehensive Negotiating Position Proposal to be Submitted to the WTO (PR(00)60F1 E P(00)134F1) $<$ http://www.copa-cogeca.be>. Disponibilidade: 20 de maio de 2007.

COPA-COGECA. (2003a) COPA and COGECA's First Reaction to the Commission's Legislative Proposal for a Mid-Term Reform of the CAP (PR(03)08F2 E P(03)13F2) $<$ http://www.copa-cogeca.be>. Disponibilidade: 3 de maio de 2007.

COPA-COGECA. (2003b) Defending European Agriculture the Fair Trade Way (WTO(03)72S4) <http://www.copa-cogeca.be>.

COPA_COGECA. (2005a) COPA and COGECA's Expectations in the WTO Negotiations on Agriculture Coming to a Fair and Balanced Agreement(WTO(05)199S2-SM) <http://www. copa-cogeca.be>. Disponibilidade: 19 de maio de 2007.

COPA_COGECA. (2005b) European Farmers: WTO Agreement Is Incomplete and One-Sided (CDP(05)99-1-SM) <http://www.copa-cogeca.be>. Disponibilidade: 19 de maio de 2007.

COPA-COGECA. (2001) Sustainable and Stable Development for European Agriculture: COPA and COGECA's Contribution to the Discussion on a Mid-Term Review of CAP (PR(01)75F1) E P(01)135F1) <http://www.copa-cogeca.be>. Disponibilidade: 10 de maio de 2007.

EISING, Rainer. (2003) Interest Groups and the European Union. Michelle Cuni, European Union Politics. Oxford: Oxford University Press. 
EUROPEAN COMMISSION, AGRICULTURE. (2003) CAP reform-a long-term perspective for sustainable agriculture $<$ http://ec.europa.eu/dgs/agriculture/index_en.htm $>$. Disponibilidade: $1^{\circ}$ de abril de 2011.

EUROPEAN COMMUNITIES. (2000a) European Communities Proposal: The Blue Box and Other Support Measures to Agriculture (G/AG/NG/W/17). <http://www.wto.org/english/ tratop_e/agric_e/ngw17_e.doc>. Disponibilidade: 10 de março de 2011.

EUROPEAN COMMUNITIES.(2000b) European Communities Proposal: Export Competition (G/AG/NG/W/34). <http://www.wto.org/english/tratop_e/agric_e/ngw34_e. doc>. Disponibilidade: 10 de março de 2011.

EUROPEAN COMMUNITIES. (2000c) European Communities Comprehensive Negotiating Proposal (G/AG/NG/W/90). <http://wwwl.wto.org/english/tratop_e/agric_e/ngw90_e.doc>. Disponibilidade: 11 de março de 2011.

FOUILLEUX, Eve. (2003), “The Common Agricultural Policy”. Michelle Cini (org.), European Union Politics. Oxford: Oxford University Press, p. 247-63.

GARRET, Geoffrey e LANGE, Peter. (1996), "Internalization, Institutions, and Political Change." Keohane, Robert O. e Milner, Helen V. Internalization and Domestic Politics. Cambridge: Cambridge University Press, p. 48-75.

GREENWOOD, Justin. (2003) Interest Representation in the European Union. New York, Palgrave Macmillan.

HOFFMANN, Andrea Ribeiro. (2003) Foreign Policy of the European Union Towards Latin American Southern Cone States (1980-2000). Frankfurt am Main, Peter Lang.

JANK, Marcos S. (2004), “Um Passo Fundamental na Rodada de DOHA da OMC”. Estado de São Paulo, 3 de agosto de 2004.

KEELER, John T. S. (1996) "Agricultural Power in the European Community: Explaining the Fate of CAP and GATT Negotiations". Comparative Politics, Vol. 28, No 2, p. 127-49.

LAWS, Forrest. (2005) EU response in Doha Round found lacking <http://www.un.org/ special-rep/ohrlls/Hongkong/News/14\%20Nov-1.htm>. Disponibilidade: 10 de março de 2011.

MAZEY, Sonia e RICHARDSON, Jeremy. (2006) "Interest groups and EU policy-making.” Jeremy Richardson, European Union: power and policy-making. Abingdon, Routledge, 3a Ed.

MILNER, Helen. (1997) Interests, Institutions and Information: Domestic Politics and International Relations. Princeton: Princenton University Press.

MINDER George e ALDEN Edward. (2005) EU approves farm tariff cuts proposal < http:// news.ft.com>. Disponibilidade: 10 de maio de 2007.

MOYER, H. Wayne. (1993), “The European Community and the GATT Uruguay Round: Preserving the Common Agricultural Policy at All Costs", in William P. Avery, Agriculture and the GATT. London, Lynne Rienner Publishers Inc.

PATTERSON, Lee Ann. (1997), "Agricultural Policy Reform in the European Community: a Three-Level Game Analysis”. International organization, n. 51, v. 1, p. 133-65.

PETERSON, John e BOMBERG, Elisabeth. (1999) Decision-Making in the European Union. New York, St Martin’s Press. 
RIEGER, Elmar. (2000). "The Common Agricultural Policy: Politics Against Markets." H. Wallace and W. Wallace (eds.) Policy-Making in the European Union, p. 179-210. Oxford, Oxford University Press, $4^{\mathrm{a}} \mathrm{Ed}$.

SMITH, Karen. (2003) EU External Relations. Michele Cini, European Union Politics. Oxford, Oxford University Press, 2003, p. 229-45.

TSEBELIS, George. (2002) Veto Players: How Political Institutions Work. Princeton: Princeton University Press.

União Europeia. (2010) Tratado de Funcionamento da União Européia <http://eur-lex.europa. eu/LexUriServ/LexUriServ.do?uri=OJ:C:2010:083:0047:0200:EN:PDF>. Disponibilidade: 10 de março de 2011.

WHITE, Brian. (2001) Understanding European Foreign Policy, New York: Palgrave.

WTO (World Trade Organization). (2001), Doha Ministerial Declaration <http://www.wto. org>. Disponibilidade: $1^{\circ}$ de março de 2011.

WTO (World Trade Organization). (2003) JOINT EC-US PAPER (JOB(03)/157 Agriculture) $<$ http://www.wto.org>. Disponibilidade: 29 de fevereiro de 2009.

WTO (World Trade Organization). (2004) Text of the "July Package" <http://www.wto.org>. Disponibilidade: 18 de março de 2008.

Recebido em 14 de julho de 2011 Aprovado em 23 de agosto de 2011

\section{Resumo}

Este artigo aborda a influência dos grupos de interesse dos produtores rurais nas posições adotadas pela UE durante a Rodada Doha. As propostas defendidas pelos dois atores foram comparadas e analisadas. Argumenta-se que as diferenças de posições encontradas podem ser explicadas pelas regras institucionais do processo decisório da Política Comercial Comum da UE. A conclusão destaca que as pressões dos grupos de interesse afetaram parcialmente as posturas da UE na Rodada Doha e não impediram que avanços se efetivassem nesse contexto.

Palavras-chave: grupos de interesse; negociações multilaterais de comércio; processo decisório da EU.

\section{Abstract}

This article deals with the influence of the agriculture interest groups in the positions adopted by EU during the Doha Round. The proposals defended by the two actors were compared and analyzed. The text argues that the distinctions of positions found can be explained by the institutional rules of the decision-making process of EU Common Trade Policy. The conclusion highlights that the pressures affected the proposals defended by EU in Doha Round negotiations, but they did not prevent advancements in this context.

Keywords: interest groups; multilateral trade negotiations; EU decision-making process. 